\title{
BUDAYA SELFIE MASYARAKAT URBAN \\ Kajian Estetika Fotografi, Cyber Culture, dan Semiotika Visual
}

\author{
Idealita Ismanto \\ Program Studi Pendidikan Seni dan Budaya \\ Pascasarjana Universitas Negeri Surabaya \\ Jalan Ketintang No. 30, Ketintang Gayungan, Surabaya \\ No. Hp.: 082245557465, E-mail: idealita.dea@gmail.com
}

\begin{abstract}
Abstrak
Penelitian ini membahas eksistensi individu yang dikonstruksi berdasarkan budaya visual. Selfie dan media sosial pada budaya visual sebagai wujud eksistensi merupakan kata yang tepat untuk menyikapi perkembangan eksistensi masyarakat. Persoalan yang diangkat membahas bagaimana budaya selfie dapat terjadi pada masyarakat urban, mengkaji budaya selfie melalui kajian estetika fotografi, cyberculture, dan semiotika visual serta perubahan sosial yang terjadi dalam masyarakat urban. Metode yang digunakan adalah observasi dan wawancara. Kegiatan analisis data dimulai dari tahap pengumpulan data, tahap reduksi, tahap penyajian data, serta tahap penarikan kesimpulan dengan penelitian kualitatif. Dapat disimpulkan bahwa praktik baru dalam cyberculture dan budaya visual yakni selfie, media sosial sebagai ranah eksistensi, masyarakat menjadikan selfie sebagai eksistensi diri yang narsisme. Masyarakat saling beradu eksistensi dengan media sosial yang berobjekkan wisata dan kesenian.
\end{abstract}

Kata kunci: budaya, selfie, cyberculture, semiotika visual

\begin{abstract}
Selfie Culture of Urban Society (Study of the Aesthetic of Photography, Cyberculture, and Visual Semiotics). This research discusses the existence of individuals constructed based on visual culture. Selfie and social media in the visual culture as a form of existence is the right word to address the development of society's existence. The issues raised would discuss how the selfie culture can occur in the urban society, how the study of selfie culture through the aesthetic of photography, cyberculture studies, and the visual semiotics and also the social changes that occur in the urban societies. The method employed was observation and interview. The data analysis activities were started from the data collection step, the reduction step, the data presentation step, and the conclusion with qualitative research. It can be concluded that the new practice in cyberculture and visual culture, which is selfie, in the social media as the realm of existence, society makes selfie as the existence of narcissistic self. Communities collide with the existence of social media consisting touristy tourists' attraction and arts.
\end{abstract}

Keywords: selfie, culture, cyberculture, visual semiotic

\section{PENDAHULUAN}

Internet merupakan produk teknologi yang banyak dimanfaatkan oleh masyarakat. Sebagai produk teknologi, internet dapat memunculkan jenis interaksi sosial baru yang berbeda dengan interaksi sosial sebelumnya. Jika pada masa lalu, masyarakat berinteraksi secara face to face communication, dewasa ini masyarakat berinteraksi di dalam dunia maya atau melalui interaksi sosial online. Melalui kecanggihan teknologi informasi, masyarakat memiliki alternatif lain untuk berinteraksi sosial.

$$
\text { Munculnya internet dapat }
$$

menghubungkan antarmanusia dari berbagai belahan dunia yang tidak saling kenal sebelumnya dengan cara mengoneksikan 
komputer dengan jaringan internet. Interaksi antarmanusia tersebut bertujuan untuk memenuhi kebutuhan hidup baik kebutuhan rohani maupun kebutuhan jasmani. Salah satunya adalah kebutuhan akan informasi. Setiap orang membutuhkan informasi sebagai bagian dari tuntutan kehidupan dan sebagai penunjang kegiatannya. Internet sangat bermanfaat bagi pemenuhan kebutuhan informasi tersebut.

Internet saat ini sebagai media sosial telah terjadi di seluruh dunia, termasuk Indonesia. Perkembangan pengguna internet juga terus bertambah. Jumlah pengguna internet di Indonesia pun sangat pesat. Dalam waktu yang relatif singkat jumlah pengguna internet di Indonesia meningkat secara signifikan. Menurut data yang dipublikasikan oleh Republika.co.id (26 Agustus 2010), penggunaan internet di dunia mengalami kenaikan yang sangat singnifikan.

Berdasarkan data dari Kementrian Komunikasi dan Informatika RI (Kemenkominfo $\mathrm{RI})$, pengguna internet kurang dari 200 juta orang pada tahun 1998. Kemudian meningkat tajam menjadi 1,7 miliar orang yang mengakses internet pada 2010. Pengguna internet di Indonesia menjadi 30 juta orang atau sekitar 12,5 persen populasi penduduk Indonesia. Selain itu menurut Asosiasi Penyelenggara Jasa Internet Indonesia (APJII), akhir tahun 2001 mencatat sebanyak 2,4 juta pengguna dan pada tahun 2007 tercatat 20 juta pengguna internet, kemudian akhir tahun 2009 tercatat 25 juta pengguna.

Menurut lembaga riset pasar e-Marketer, populasi netter Tanah Air mencapai 83,7 juta orang pada 2014. Angka yang berlaku untuk setiap orang yang mengakses internet setidaknya satu kali setiap bulan itu mendudukkan Indonesia di peringkat ke- 6 terbesar di dunia dalam hal jumlah pengguna internet. Pada 2017, eMarketer memperkirakan netter Indonesia bakal mencapai 112 juta orang, mengalahkan Jepang di peringkat ke-5 yang pertumbuhan jumlah pengguna internetnya lebih lamban. Secara keseluruhan, jumlah pengguna internet di seluruh dunia diproyeksikan akan mencapai 3 miliar orang pada 2015. Tiga tahun setelahnya, pada 2018, diperkirakan sebanyak 3,6 miliar manusia di bumi akan mengakses internet setidaknya sekali tiap satu bulan.

Abad ke-21 adalah abad visual. Gejala visual terdapat di mana-mana. Berbagai tanda visual telah menjadi bahasa komunikasi visual yang memberikan ruang interpretasi dan reinterpretasi tentang pengalaman dan realitas. Gejala ini dalam konteks dunia hari ini di dorong oleh kehadiran berbagai media komunikasi yang secara masif dijadikan instrumen paling representatif untuk membentuk makna diri di dalam dunia post-modern (Djuli, 2016).

Perkembangan media sosial yang terus diakses oleh penduduk Indonesia akhirnya memunculkan fenomena sosial tersendiri yang disebut dengan cyberculture. Di dalam cyberculture terdapat interaksi antara manusia yang satu dengan manusia yang lain khususnya dalam hal komunikasi dalam aspek visual. Cyberspace memberi ruang yang bebas bagi tiap individu untuk melakukan tindakan apa pun. Hal ini dapat dilihat dalam masyarakat urban yang memiliki kecanggihan teknologi dalam smartphone yang mereka gunakan di kehidupan sehari-hari. Mereka mendokumentasikan kehidupan mereka dengan mengunggahnya di media sosial dalam bentuk budaya selfie.

Tujuan utama artikel ini ialah memberi gambaran tentang beberapa hal yang dipandang penting dalam budaya selfie. Hal-hal yang akan dibahas berkaitan dengan budaya selfie yang terjadi pada masyarakat urban dan budaya selfie melalui kajian estetika fotografi, cyberculture, 
dan semiotika visual serta perubahan sosial yang terjadi dalam masyarakat urban.

\section{METODE PENELITIAN}

Penelitian bertujuan untuk mendapatkan data tentang budaya selfie dalam masyarakat urban. Metode yang digunakan adalah kualitatif deskriptif. Metode kualitatif digunakan untuk mendapatkan data yang mendalam, suatu data yang mengandung makna. Menurut Saebani (2012), makna adalah data yang sebenarnya, data yang pasti dan merupakan suatu nilai di balik data yang tampak.

Makna yang berusaha untuk ditunjukkan dalam penelitian ini ialah budaya selfie dalam masyarakat urban yang dikaji melalui cyberculture dan semiotika visual. Jenis penelitian yang digunakan adalah deskriptif, yakni untuk mendeskripsikan terjadinya budaya selfie pada masyarakat urban dan perubahan sosial masyarakat dengan kajian cyberculture dan semiotika visual.

\section{PEMBAHASAN}

\section{Kajian Estetika Fotografi dalam Budaya Selfie Masyarakat Urban}

Secara sederhana, estetika adalah ilmu yang membahas keindahan, bagaimana bisa terbentuk, dan bagaimana seseorang bisa merasakannya. Herbet Read dalam bukunya The Meaning of Art merumuskan keindahan sebagai suatu kesatuan arti hubungan bentuk yang terdapat di antara pencerapan-pencerapan inderawi (Dharsono, 2014).

Dalam buku Kisah Mata salah satu karya Seno Gumira Ajidarma tertulis, bahwa pada tahun 1764 dalam buku yang diterjemahkan ke dalam bahasa Inggris, Notes on Painting, Francesco Algarotti dari Venesia menulis:
"Biarlah para pelukis muda, karena itu, mulaiseawalmungkinuntukmempelajari gambar-gambar Ilahiah ini, jika ia tidak akan pernah merenungkannya... Pelukis harus menggunakan camera obscura seperti para naturalis dan astronom memanfaatkan mikroskop dan teleskop; dimana segenap peralatan ini samasama membuat alam diketahui dan dihadirkan kembali" (Ajidarma, 2007).

Kutipan paragraf tersebut menjelaskan bahwa kamera adalah sebuah mesin untuk melihat, yang membantu pelukis mengambar potret wajah atau melukis pemandangan dalam studio (Ajidarma, 2007).

Kamera obscura merupakan alat bantu menggambar para seniman Renaissance pada abad ke 15 yang kemudian berkembang dengan kelengkapan berbagaiapparatus (lensa, diafragma, pengatur asa, light-meter, dll) untuk menjadi kamerafotografi yang dikenal saat ini (Soedjono, 2006). Fungsi awal dari kamera obscura memang diarahkan sebagai alat bantu menggambar pada saat itu, kemudian berkembang menjadi kamera pada saat ini yang menjadi suatu bagian dari seni itu sendiri yaitu seni fotografi. Foto memang merupakan usaha untuk meyakinkan, bahwa apa yang dipotret dapat hadir kembali dalam hasil karya berupa foto, persis seperti mata manusia melihatnya (Ajidarma, 2007).

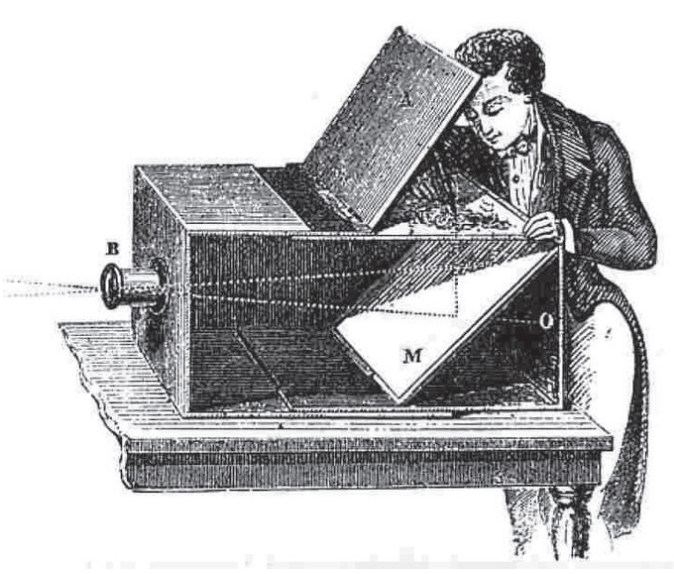

Gambar kamera obscura 
Fotografi memiliki bermacam-macam manfaat dengan tujuan baik untuk dokumentasi penelitian maupun sebagai media dalam ranah estetika. Estetika fotografi meliputi dua tataran, estetika pada tataran ideational dan estetika pada tataran technical (Soedjono, 2006). Tataran ideational adalah nilai estetika yang berhubungan dengan gagasan, ide atau suatu konsep. Sementara itu, tataran technical adalah penggalian nilai estetika melalui teknik pemotretan. Pierce menggolongkan tanda menjadi tiga yaitu ikon, indeks dan simbol. Di dalam foto selfie yang ada di masyarakat urban dapat dianalisis ketiga tanda tersebut.

Fotografi memiliki dua fungsi, pertama sebagai media untuk merekam kenyataan dan kedua sebagai medium ekspresi artistik. Secara kodratnya sebagai alat perekam, fotografi memiliki hubungan yang dekat dengan keseharian dan perkembangan kehidupan sosial budaya dalam masyarakat. Ia memperlihatkan kehidupan urban atau pedesaan, kehidupan secara alami, modernitas, wajah orang-orang, landscape, kultur, fashion, kegembiraan, keindahan lingkungan, kesedihan, kehancuran, perang dan perubahan dalam masyarakat. Menurut editor foto majalah Life dari 19371950, Wilson Hicks, foto jurnalistik adalah kombinasi dari kata dan gambar yang menghasilkan suatu kesatuan komunikasi saat ada kesamaan antara latar belakang pendidikan dan sosial pembacanya (Alwi, 2004).

\section{Kajian Cyberculture dalam Budaya Selfie Masyarakat Urban}

Arti cyberculture secara harfiah dapat diterjemahkan sebagai budaya cyber. Dengan kata lain cyberculture adalah segala budaya yang telah atau sedang muncul dari penggunaan jaringan komputer untuk komunikasi, hiburan, dan bisnis. Cyberculture juga mencakup tentang studi berbagai fenomena sosial yang berkaitan dengan internet dan bentuk-bentuk baru komunikasi jaringan lainnya seperti komunitas online, game multiplayer online, jejaring sosial, texting, dan segala hal yang berkaitan dengan identitas, privasi, dan pembentukan jaringan (Bell, 2001).

Manifestasi dari cyberculture meliputi berbagai interaksi manusia yang dimediasi oleh jaringan komputer. Hal-hal tersebut mencakup aktivitas, kegiatan, permainan, tempat dan metafora, dan termasuk basis beragam aplikasi. Beberapa didukung oleh perangkat lunak khusus dan bekerja pada protokol web umum diterima.

Di Indonesia cyberculture mulai berkembang sejak internet masuk ke Indonesia. Sejarah internet Indonesia dimulai sejak tahun 1920 (zaman pra-teknologi informasi) dan terus berkembang hingga tahun 1990. Tahun 1990 internet awal mulai masuk dan digunakan untuk kepentingan surat-menyurat elektronik (e-mail) oleh pemerintah dan lembaga pendidikan. Tahun 1996 hingga tahun 1998 internet di Indonesia mulai dimaksimalkan untuk kepentingan pendidikan, dan disosialisasikan hingga ke tingkat RT dan RW, dikenal dengan istilah kampung cyber dan RT/RW NET (Ida, 2016).

Fenomena interaksi sosial online saat ini merupakan salah satu karakteristik dari masyarakat informasi. Perubahan masyarakat yang dulunya hanya mengenal interaksi sosial secara nyata (face to face), tetapi saat ini seseorang dapat berinteraksi dengan orang lain di internet. Masyarakat informasi pertama kali diperkenalkan oleh Daniel Bell. Masyarakat informasi tersebut ditandai dengan semakin banyak munculnya sektor ekonomi industri 
yang berbasis informasi pada tahun 1960an, mulai dari proses produksi hingga proses distribusi yang disertai dengan informasi dalam bentuk teknologi informasi (Dyah, 2016).

Di dalam cyberculture terdapat budaya visual. Budaya visual adalah tautan wujud kebudayaan konsep (nilai) dan kebudayaan materi (benda) yang dapat segera ditangkap oleh indera visual (mata) dan dapat dipahami sebagai model pikiran manusia untuk meningkatkan kualitas hidupnya. Budaya visual bukan hanya sekadar "baju" dari sebuah peradaban material, melainkan sebuah hakikat dari struktur budaya pembentuknya. Pilar-pilar tersebut adalah kreativitas nilai, inovasi, penciptaan teknologi baru, ideologi komunikasi, politik kebudayaan, dinamika sosial, tatanan ekonomi global, hingga segala sesuatu yang sifatnya mendasar dalam membentuk bangun sebuah peradaban (Blossom, 2009).

Sementara itu, budaya visual (visual culture) merujuk pada kondisi visual menjadi bagian dari kehidupan sosial. Bahkan menurut Rose (2001), modernitas saat ini berpusat pada aspek visual. Visual menjadi hal yang utama pada postmodernitas. "postmodern is a visual culture" (Mirzoeff, 1999).

Budaya selfie yang marak terjadi pada era globalisasi ini terpengaruh oleh budaya visual yang melekat dalam negara kita. Indonesia adalah negara yang berperan dalam hal konsumerisme smartphone dan penggunaan jejaring sosial nomor tiga dunia, yaitu Facebook.

Di dalam budaya selfie terdapat juga teori narsisme yang merajela dalam cyberspace. Konsep dan istilah narsisme berawal dari sebuah mitologi Yunani kuno tentang seorang pemuda yang bernama Narsisus. Pemuda ini sangat mengagumi dan jatuh cinta pada refleksi gambar dirinya. Ia sangat ingin menjamah dan memiliki wajah yang dilihatnya dalam air, namun setiap kali ia mengulurkan tangannya untuk meraih refleksi dirinya, bayangan itu kemudian menghilang (Harmawan, 1999).

Bagaimanakah keterkaitan budaya selfie dengan narsisme? Sebelumnya penulis ingin menjelaskan tentang selfie. Selfie adalah singkatan dari self portrait, yang artinya foto yang diambil dari kamera handphone atau kamera digital oleh orang itu sendiri. Mereka yang suka selfie ini menyebarkan hasil dari foto mereka ke media sosial, seperti Facebook, Twitter, Instagram, dan Path. Karena memang saat ini, media sosial banyak menyediakan media/aplikasi yang memang menggaet masyarakat untuk menyukai selfie dan narsis. Selfie biasanya digunakan untuk mengambil pose kasual dengan menggunakan kamera yang diarahkan pada diri sendiri. Selfie biasanya menggunakan kamera digital atau kamera handphone, ada juga yang melakukan selfie dengan bantuan cermin. Pada tahun 2013, secara resmi kata selfie masuk ke dalam Oxford English Dictionary.

Akan tetapi, tidak selamanya selfie berarti narsis. Bisa saja dia hanya selfie hanya untuk kesenangan sesaat. Sementara mereka yang narsis bisa menjadi seorang narsistik atau mengalami gangguan kepribadian. Penderita narsistik percaya bahwa mereka lebih unggul dan kurang memerhatikan perasaan orang lain. Namun di balik itu semua, sebenarnya dia memiliki harga diri yang rapuh dan rentan terhadap kritik.

Di dalam cyberculture terdapat teori fenomenologi, yaitu studi sosiologi terhadap sesuatu yang berhubungan dengan pengalaman dan kesadaran dalam diri dan akan mencari pengalaman pengalaman dan esensi yang telah kita alami, melalui belajar dari pengalaman 
sadar melalui satu manusia dan sudut pandang subjektif.

"Fenomenologi kritik" yang dituliskan oleh seorang ahli fenomenon post Amerika yang bernama Don Ihde (1990), menjelaskan empat tipe hubungan manusia teknologi/ informasi, yaitu: (1) hubungan perwujudan, sebagai contoh seperti sebuah kacamata, yang dibawa ke tubuh adalah pengalaman dan yang menengahi dunia luar melalui peningkatan kemampuan untuk melihatnya; (2) hubungan hermeneutik, teknologi mewakili dunia, seperti dalam kasus peta (yang dibutuhkan adalah ketrampilan dari si pembaca peta untuk merepresentasikan pemandangan yang ada); (3) alteritas hubungan, seperti perasaan mesin bekerja melawan kamu, mesin yang terkait untuk seolah olah itu adalah sebuah menghidupkan lain (berteriak komputer Anda untuk kehilangan file); dan (4) hubungan latar belakang: hal seperti pencahayaan dan panas yang tersedia dalam hidup kita tetapi tanpa kita sadari, kita inginkan atau kita lepaskan.

Sekarang, semua hubungan ini dapat membantu kita dalam mengerti bagaimana sesuatu seperti internet yang ada dalam penggunaan kehidupan sehari-hari, bagaimana dengan pengembangan genre yang terjadi. Ihde juga menjelaskan tentang dualisme dampak yang dihasilkan oleh teknologi baru, yaitu membuat semuanya lebih mudah, tetapi yang lainnya tampak menjadi sulit.

Perkembangan internet memang bergerak pesat. Cyberspace yang hanya sebuah khayalan dan ramalan dalam sebuah novel fiksi di tahun 1984 (Neuromancer, William Gibson) telah benar-benar lahir dan bahkan menawarkan realitas dan kebudayaan tersendiri, yaitu cyberculture. Kita tidak bisa menutup mata bahwa, kebudayaan ruang telah disubstitusi oleh kebudayaan pascaruang cyberspace. Muncullah cyberculture dengan segudang nilai yang diusungnya.

\section{Hiperrealitas Jean Baudrillard}

Saat ini simulasi adalah realitas secara menyeluruh: politik, sosial, sejarah dan ekonomi yang mulai sekarang menggabungkan dimensi simulasi hiperrealisme (Baudrillard, 1983a). Budaya selfie merupakan hiperrealitas karena di dalamnya melukiskan realitas virtual gambaran kehidupan yang lebih nyata dibandingkan dengan kehidupan nyata itu sendiri. Yang nyata lenyap karena longsoran simulasi dan yang muncul adalah realitas yang mengatasi realitas real (hyperreality), realitas yang cantik dari yang cantik, lebih benar dari yang benar. Hiperrealitas tidak diproduksi, akan tetapi selalu siap direproduksi (Baudrillard, 1993).

Era simulasi dan hiperrealitas, menurut Baudrillard (1983b), sebagai bagian rangkaian fase citraan. Rangkaian itu dijelaskan sebagai berikut: (1) citraan sebagai refleksi dasar dari realitas; (2) citraan menutupi dan mendistorsi realitas; (3) citraan menutup ketiadaan atau lenyapnya dasar dari realitas; dan (4) citraan melahirkan ketidakterhubungan terhadap berbagai realitas apa pun, citraan bukanlah kemurnian simulakrum itu sendiri .

Hiperrealitas menciptakan satu kondisi yang di dalamnya kepalsuan berbaur dengan keaslian, masa lalu berbaur masa kini, fakta bersimpang siur dengan rekayasa, tanda melebur dengan realitas, dusta bersenyawa dengan kebenaran. Kategori-kategori kebenaran, kepalsuan, keaslian, isu, realitas seakan-akan tidak berlaku lagi di dalam dunia seperti itu.

Keadaan dari hiperrealitas ini membuat masyarakat modern ini menjadi berlebihan 
dalam pola mengonsumsi peralatan teknologi modern seperti handphone canggih dan alat lainnya untuk menciptakan foto selfie. Yang real dibuat jadi tidak nyata oleh "hyperreal", dan simulasi menjadi lebih besar dari kebenaran. Ketika tidak ada lagi kebenaran atau realitas, maka tanda dan kode tidak lagi melambangkan sesuatu, simulasi dengan demikian membunuh makna secara absolut (Gane, 1994).

\section{Kajian Semiotika Visual dalam Budaya Selfie Masyarakat Urban}

Sebelum menjelaskan hubungan semiotika visual dengan budaya selfie, terlebih dahulu penulis akan menjelaskan pengertian semiotika visual. Semiotik atau semiotika berasal dari kata Yunani semeion yang berarti "tanda". Konsep semiotika sebagai ilmu tanda semakin berkembang, tidak hanya berlaku dalam sastra, tetapi juga dalam ilmu seni, antropologi, dan filsafat (Barthes, 2014).

Roland Barthes seperti dikutip oleh Fiske (1990) menyebutkan bahwa semiotika adalah ilmu yang mempelajari tanda dan hubungan struktural antara penanda atau signifier (ungkapan, kata, tulisan dan gambar) sebagai tema pertama atau penanda atau signified (konsep atau makna).

Foto adalah gambar yang memiliki banyak ciri yang sama dengan berbagai citra yang sama dengan berbagai citra yang lain (Cf.Mclean, 1973). Salah satu karakteristik yang paling menonjol dari sebuah foto adalah produksi mekanisme semunya. Tomas (1982) bahkan mengintrepretasikannya sebagai sebuah ritual, dalam suatu proses psiko-kimiawinya di mana referennya merupakan penyebab penanda gambar.

Kekhususan indeksikalitas tanda fotografi telah diakui oleh beberapa ahli semiotik. Misalnya, Eco mengakarakterisasikan foto sebagai sebuah cetakan atau jejak, suatu tanda "yang termotivasi tetapi bersifat heteromaterial". Menurut interpretasi Barthes (1980), "fotografi selalu membawa referennya sendiri" karena ia merupakan "sesuatu yang dapat menceritakan masa lalu".

Aspek indeksikalitas yang berbeda adalah acuan fotografis pada pengalaman pribadi. Sebagaimana dijelaskan Berger, fotofoto pribadi "memiliki arti eksistensi yang penting. Foto-foto tersebut berkata, " Lihatlah kami ada! Aku telah melihat berbagai hal, aku telah melakukan berbagai hal" (Berger, 1984). Untuk budaya selfie sendiri, keterkaitan pengalaman pribadi sangat berpengaruh dalam proses pengambilan foto selfie.

\section{Foto dalam Budaya Media}

Dengan istilah budaya media dimaksudkan budaya yang lahir dan berkembang lewat media massa atau teknologi informasi baru (new technology of information) atau media baru (new media). Kini juga dipakai istilah budaya media baru (new media culture). Dalam uraian ini terlihat fungsi unik dari foto sebagai salah satu bentuk representasi, fungsi yang tidak dimiliki oleh bentuk lain seperti tulisan dan film (sekalipun film mengambil bahan dasarnya dari foto). Sebagai that-hasbeen,noeme foto berbeda dengan noeme tulisan (bahasa) yang fiksional atau juga berbeda dengan noeme film (that-has-passed) yang menghadirkan realitas seperti biasanya. Apa yang sudah terlihat sampai sekarang adalah usaha Barthes untuk menemukan noeme foto dan fungsinya bagi kita (spectator) untuk mengembangkan self (diri) kita. 
Perubahan Sosial Masyarakat yang Terjadi dalam Masyarakat Urban Berhubungan dengan Budaya Selfie

Definisi perubahan sosial menurut Wilbert Moore dalam Lauer (2001) adalah perubahan penting dari struktur sosial dan yang dimaksud struktur sosial adalah pola-pola perilaku dan interaksi sosial. Wilbert Moor memasukkan ke dalam definisi perubahan sosial berbagai ekspresi mengenai struktur, seperti norma, nilai dan fenomena kultural, sehingga jelaslah bahwa definisi demikian itu serba mencakup (Ranjabar, 2015). Fenomena selfie yang merebak dalam masyarakat urban tidak dapat terlepas dari budaya visual dan kemajuan teknologi dan sekarang berada dalam abad visual yang selalu dituntut untuk cepat dalam melakukan inovasi dalam setiap hal.

Teori revolusi menyatakan bahwa perubahan sosial dan kebudayaan pada hakikatnya berlangsung dengan cepat dan menyangkut dasar-dasar atau sendi-sendi pokok kehidupan masyarakat. Di dalam revolusi perubahan-perubahan yang terjadi dapat direncanakan terlebih dahulu atau tanpa rencana.

Dalam konteks kehidupan kontemporer (post-modern) seperti yang terjadi sekarang ini, bahasa visual sangat diandalkan dalam berbagai bentuk komunikasi visual. Sementara itu, masyarakat global yang hidup di sebuah jagat raya maya memasuki ruang kehidupan yang menawarkan pengalaman baru yang penuh kejutan. Menurut Piliang (2003) melalui sebuah tulisan pengantar dalam buku Mark Slouka bertajuk Ruang yang Hilang: Pandangan Humanis tentang Budaya Cyberspace yang Merisaukan, "Jagat raya maya itu dianggap lebih menyenangkan dibandingkan dunia nyata itu sendiri" (Djuli, 2016).
Meskipun selfie menandakan rasa agensi manusia (yaitu, itu adalah salah satu foto sengaja mengambil dari diri sendiri, sering diberitahukan pada manusia lainnya), narsis diciptakan, ditampilkan, didistribusikan, dilacak, dan menghasilkan uang melalui himpunan agen bukan manusia. Politik kumpulan ini menjadikan selfie umumnya dianggap hanya sikap yang terjadi kedekatan dan kehadiran menjadi pengingat bahwa setelah apa memasuki ruang digital, itu langsung menjadi bagian dari infrastruktur super publik digital, hidup lebih lama waktu dan tempat di mana ia asli diproduksi, melihat, atau diedarkan. Hal ini mungkin untuk alasan ini bahwa selfie berfungsi baik sebagai praktek kehidupan sehari-hari dan sebagai objek politisasi wacana tentang bagaimana orang terwakili, dokumen, dan berbagi perilaku mereka (Senft, 2015).

Perubahan yang signifikan terlihat adalah pada anak remaja perempuan dan lakilaki di perkotaan sangat sering meng-upload foto selfie mereka di media sosial. Media sosial adalah sebuah media online, dengan para penggunanya bisa dengan mudah berpartisipasi, berbagi, dan menciptakan isi meliputi blog, jejaring sosial, wiki, forum dan dunia virtual. Blog, jejaring sosial, dan wiki merupakan bentuk media sosial yang paling umum digunakan oleh masyarakat di seluruh dunia. Pendapat lain mengatakan bahwa media sosial adalah media online yang mendukung interaksi sosial dan media sosial menggunakan teknologi berbasis web yang mengubah komunikasi menjadi dialog interaktif.

Pesatnya perkembangan media sosial kini dikarenakan semua orang seperti bisa memiliki media sendiri. Jika untuk memiliki media tradisional seperti televisi, radio, atau koran dibutuhkan modal yang besar dan 
tenaga kerja yang banyak, lain halnya dengan media. Seorang pengguna media sosial biasa mengakses menggunakan media sosial dengan jaringan internet bahkan yang lambat sekalipun. Pengguna media sosial dengan bebas bisa mengedit, menambahkan, memodifikasi baik tulisan, foto, gambar, video, grafis, dan berbagai model content lainnya.

Perubahan sosial yang terjadi dalam masyarakat urban akhirnya membuat semua orang harus terus menyebarkan semua hal tentang dirinya sendiri, apa pun yang dilakukan, ia mempunyai kewajiban dan keinginan untuk menguploadnya di jejaring sosial. Kelemahan dalam jejaring sosial ini menyebabkan interaksi interpersonal secara tatap muka (face to face) cenderung menurun. Orang lebih memilih untuk menggunakan situs jejaring sosial karena lebih praktis. Di lain pihak, kemunculan situs jejaring sosial ini membuat anak muda tidak dapat tidak mengakses internet. Dalam kadar yang berlebihan, situs jejaring sosial ini secara tidak langsung membawa dampak negatif, seperti kecanduan yang berlebihan dan terganggunya privasi seseorang.

\section{SIMPULAN}

Budaya selfi dalam masyarakat urban merupakan kemajuan yang signifikan dalam perkembangan teknologi cyberspace dan menjadikannya sebagai cyberculture. Ada beberapa alasan yang bisa dipaparkan dalam foto selfie. Pertama, budaya selfie dalam masyarakat urban dapat juga menjadi moral panic karena di dalam segala aktivitas yang dilakukan harus diunggah ke media sosial dan jejaring sosial agar mendapat pengakuan dari masyarakat tentang eksistensi diri. Sebagai makhluk sosial, manusia ingin berhubungan dengan manusia lainnya, dan dengan budaya selfie, mereka dapat mengekspresikan segala bentuk perasaan mereka atau sifat narsisme mereka sebagai bentuk dari hiper semiotik, yaitu sebuah kecenderungan yang melampaui semiotika konvensional (khususnya semiotika struktural), yang beroperasi dalam sebuah kebudayaan yang di dalamnya berkaitan dengan relasi lainnya yang lebih kompleks antara tanda, makna dan realitas, khususnya relasi simulasi.

Kedua, selfie juga menandakan bahwa pengguna menggunakan keterbukaan diri (self disclosure) di media sosial. Efek keterbukaan diri itu adalah interaksi dan komunikasi yang terjadi dengan pengguna lain akan semakin erat. Bahkan dalam beberapa kasus, pengunggahan foto diri menyebabkan bertambahnya jalinan pertemanan yang baru sehingga jaringan sosial yang dimiliki semakin luas.

Ketiga, foto diri merupakan suatu narsisme digital. Sebuah foto diri selain sebagai eksistensi diri, juga sebagai bentuk pertunjukan di depan panggung untuk menarik kesan pengakses atau pengguna lain dalam jaringan pertemanan di media sosial. Keterkaitan selfie dengan narsisme karena selfie adalah singkatan dari self portrait, yang artinya foto yang diambil dari kamera handphone atau kamera digital oleh orang itu sendiri. Mereka yang menyukai selfie ini menyebarkan hasil dari foto mereka ke media sosial, seperti Facebook, Twitter, Instagram, dan Path. Karena memang saat ini, media sosial banyak menyediakan media atau aplikasi yang memang menggaet masyarakat untuk menyukai selfie dan narsis. Selfie biasanya digunakan untuk mengambil pose kasual dengan menggunakan kamera yang diarahkan pada diri sendiri. Selfie biasanya menggunakan kamera digital atau kamera handphone. Yang paling banyak berfoto selfie adalah perempuan. 
Berbeda dengan potret tradisional, selfie tidak berprentesi membuat klaim yang tertentu. Selfie memiliki arah yang berbeda atau tanpa arah sekalipun. Meskipun, seorang teoretikus seperti Susan Sontag dan Ronald Barthes melihat melankoli dan tanda-tanda kematian dalam setiap fotografi, selfie tidak berlangsung sepanjang abad. Selfie merupakan bahasa kita kepada dunia. Selfie merupakan catatan harian visual mini yang membesar-besarkan mengurangi, mendramatisasi, yang berkata, "Aku di sini: lihatlah aku” (Rulli, 2015).

\section{KEPUSTAKAAN}

Ajidarma, S. (2007). Kisah Mata: Perbincangan tentang Ada. Yogyakarta: Galang Press.

Alwi, A. M. (2004). Foto Jurnalistik: Metode Memotret dan Mengirim Foto ke Media Massa. Jakarta: Bumi Aksara.

Barthes, R. (1980). Camera Lucida: Reflections on photography. London: Cape.

Barthes, R. (2014). Imaji Musik Teks: Analisis Semiologi atas Fotografi, Iklan, Film, Musik, Alkitab, Penulisan dan Pembacaan serta Kritik Sastra. Yogyakarta: Jalasutra.

Baudrillard, J. (1983a). Simulations. New York: Semiotext (e).

Baudrillard, J. (1983b). The Shadow of the Silent Majorieties, or The End of the Social and Other Essays. New York: Semiotext (e).

Baudrillard, J. (1993). The Transparancy of Evil: Essays On Extreme Phenomena. London: Verso.

Bell, D. (2001). An Introduction to Cybercultures. New York: Routledge.

Berger, A. A. (1984). Signs in Contemporary Culture: An Introduction to Semiotics. London: Longman.

Blossom, J. (2009). Content Nation: Surviving and Thriving as Social Media Changes Our Work, Our Lives and Our Future. Indianapolis: Wiley-Blackwell.

Cf.Mclean, R. (1973). Photography as Visual Research. New York: Routledge.

Dharsono. (2014). Seni Rupa Modern. Bandung: Rekayasa Sains.

Djuli, D. (2016). Paradigma Memahami Realitas Post-Modern;Seminar Nasional Literasi Visual. Surabaya: Universitas Negeri Surabaya.
Dyah, S. (2016). Media Sosial Interaksi, Identitas dan Modal Sosial. Jakarta: Kencana.

Fiske, J. (1990). Introduction to Communication Studies (2 ed.). London: Routledge.

Gane, M. (1994). "Radical Theory: Baudrillard and Vulnerability in Theory Culture and Society". Radical Theory, 12 (4).

Harmawan, L. (1999). Fenomena Narsisisme Tidak Sehat di Kalangan Profesi Muda Jakarta. Universitas Indonesia.

Ida, R. (2016). Studi Media dan Kajian Budaya. Kencana.

Lauer, R. H. (2001). Perspektif Tentang Perubahan Sosial, Alih Bahasa, Alimandan S.U (Perpective on Social Change). Jakarta: Rineka Cipta.

Mirzoeff, N. (1999). An Introduction to Visual Culture. London: Routledge.

Piliang, Y. A. (2003). Hipermsemiotika: Tafsir Cultural Studies atas Matinya Makna. Yogyakarta: Jalasutra.

Ranjabar, J. (2015). Perubahan Sosial: Teori- Teori dan Proses Perubahan Sosial serta Teori Pembangunan. Bandung: Alfabeta.

Rose, G. (2001). Visual Methologies. Sage Pub.

Rulli, N. (2015). Media Sosial Perspektif Komunikasi, Budaya,dan Sosioteknologi: Simbiosa. Rekatama Media.

Saebani, A. (2012). Metodologi Penelitian. Surabaya: Predana Media Group.

Senft, T. M. et. al. (2015). "What Does the Selfie Say? Investigating a Global Phenomenon". International Journal of Communication, 9, 1588-1606.

Soedjono, S. (2006). Pot Pourri Fotografi. Jakarta: Penerbit Universitas Trisakti.

Tomas, D. (1982). "The Ritual of Photography". Semiotica, 2, 1-25. 